\title{
EVALUATION OF ALBUMIN COATED XENOGRAFT WITH PLATELET RICH FIBRIN IN SOCKET PRESERVATION AFTER TOOTH EXTRACTION
}

\author{
Mohamed Elsayed Abdulaziz ${ }^{1}$, Tarek Abdulsamad ${ }^{2}$ and Ahmed Ahmed Hussien Elfeky ${ }^{3}$
}

\begin{abstract}
Objective: The present study was performed to evaluate the effect of addition of human serum albumin and platelet rich fibrin to xenograft bone (OneGraft natural collagenated bovine bone graft 1.0 -2.0mm grain size Bioimplon, Germany) for socket preservation Material and Methods: Twenty healthy patients seeking treatment for badly broken teeth (lower premolars and molars) were randomly selected from the out-patient clinic of Department of Oral and Maxillofacial surgery, Faculty of Dental Medicine, Al Azhar University, Cairo, Boys, 10 patients in each group. In the first (study) group, the patients will be subjecting to extraction of badly decayed non restorable tooth then insertion of human albumin coated xenograft bone (OneGraft natural collagenated bovine bone graft $1.0-2.0 \mathrm{~mm}$ grain size Bioimplon, Germany) and platelet rich fibrin. In the second (controlled) group, the patients will be subjecting to extraction of badly decayed non restorable tooth without xenograft insertion. CBCT was done to evaluate; bone density, alveolar bone height at the site of extraction and bone graft addition. Bone Density and height was measured at alveolar bone crest \& middle of the socket at region of interest (ROI) immediately \& at 6 months post operatively. Results: In albumin coated xenograft with PRF group showed less decrease in buccal, lingual height and width and increase in bottom of socket. It was found that albumin coated xenograft with PRF group had an increase in bone density measurements. Conclusion: Post extraction alveolar ridge resorption is an inevitable process, the use of albumin coated xenograft with PRF were effective in socket preservation and significantly minimized ridge resorption in all dimensions. Appling of albumin coated xenograft with PRF to the alveolar socket could be more accelerate the bone healing and shorting the time period for rehabilitation than the normal sequence of healing.
\end{abstract}

KEY WORDS: Human serum albumin, Platelet rich fibrin, xenograft, socket preservation, cone beam computed tomography

\section{INTRODUCTION}

After tooth extraction the dimensional change of an alveolar ridge is inevitable over time. Bone resorption is more rapid in cases of existing periodontal disease, inflammatory periapical lesions, or serious previous bone wall defects after the extraction ${ }^{(1)}$. The soft tissue collapses into the defect hindering normal and natural healing ${ }^{(1,2)}$. Bone resorption after tooth extraction can make the implant placement difficult. It also makes oral hygiene care around the prosthesis difficult. Therefore, various methods were attempted to minimize alveolar bone resorption.

1. Masters Candidate, Department of Oral and Maxillofacial Surgery. Faculty of Dental Medicine, (Boys - Cairo), Al-Azhar University

2. Professor, Department of Oral and Maxillofacial Surgery, Faculty of Dental Medicine, (Boys - Cairo), Al-Azhar University

3. Assistant Professor, Department of Oral and Maxillofacial Surgery. Faculty of Dental Medicine, (Boys Cairo), Al-Azhar University

-Corresponding author: dr.m-elsayed@hotmail.com 
Despite modern bone grafting techniques, management of socket bone defects remains a significant surgical challenge. An ideal bone graft should feature good mechanical strength and significant osteoinductive, osteoconductive and osteogenic capabilities ${ }^{(3)}$. Autologous human bone graft possesses all these characteristics, but it is not available in large quantities, and complications of the donor site also limit its use ${ }^{(4)}$. Many different osteoinductive materials have been tested in an attempt at improving bone healing, bone morphogenic proteins (BMPs), demineralised bone matrix (DBM) and platelet rich plasma (PRP) being the most widely studied varieties ${ }^{(5)}$.

Allograft and xenografts address disadvantages of autografts, but they are less osteoconductive, are not vascularized, exhibit poor mechanical properties and also carry an increased risk of infection. Serum albumin is a well-known proliferative factor in cell culture, has the ability to induce mesenchymal stem cell growth on the surface of bone allografts ${ }^{(6)}$. Since it is obvious that the proliferation of bone-forming cells is the rate-limiting factor in graft remodelling, one may postulate that serum addition to bone substitutes may improve the colonisation of the graft by host cells. In previous in vitro experiments showed that freeze-dried serum albumin coating on human allografts provides a convenient milieu for mesenchymal stem cell (MSC) proliferation ${ }^{(7)}$.

Albumin coated human allografts were also implanted in a rat nonunion femur model in vivo, where found a significant defect consolidation at four weeks after implantation ${ }^{(8)}$. At this time point, albumin coated allografts successfully bridged nonunion bone defects, while uncoated grafts failed.

Later, investigation of the safety and surgical applicability of albumin-coated allografts in a human experiment, during which albumin coated allografts were implanted in 10 cases of aseptic revision arthroplasty as a support for the metal prosthesis ${ }^{(9)}$. These experiments successfully showed the applicability of albumin coating and raised hope for better clinical outcome.

\section{SUBJECTS AND METHODS}

In the current study twenty healthy patients seeking treatment for badly broken teeth (lower premolars and molars) were randomly selected from the out-patient clinic of Department of Oral and Maxillofacial surgery, Faculty of Dental Medicine, Al Azhar University, Cairo, Boys. The age of selected patients range from (18-65) years.

Inclusion criteria were patient with badly broken, non-restorable, or periodontally hopeless teeth with good oral hygiene, ranged from 18 to 65 years old.

Exclusion criteria were patient suffering from systemic conditions that affect bone healing, acute preapical pathosis, sever periodontal disease, heavy smoker, patient with uncontrolled medically compromised state or on chemo and/or radiotherapy.

\section{Sample size calculation:}

According to analyses of the width of the alveolar ridge ${ }^{(10)}$, sample size calculation was undertaken via $G$ power version 3.1 statistical software based on the following pre-established parameters: an alpha-type error of 0.05 , a power test of 0.80 , a total sample of at least 20 subjects (10 subjects for each group) appeared to be sufficient.

\section{Grouping :}

All participating patient will randomly dividing into two groups, group A and B, according to methods of treatment. Twenty patients will be included in this study, 10 patients in each group. In the first (study) group, the patients will be subjecting to extraction of badly decayed non restorable tooth then insertion of human albumin coated xenograft bone (OneGraft natural collagenated bovine bone graft $1.0-2.0 \mathrm{~mm}$ grain size Bioimplon, Germany) and platelet rich fibrin. In the second (controlled) group, the patients will be subjecting to extraction of badly decayed non restorable tooth without xenograft insertion.

\section{Pre-operative evaluation:}

All patients were prepared for surgery by the following: 


\section{A. Clinical examination:}

All the patients were subjected to a complete history taking, including: name, age, gender, occupation, residency, chief complaint, general condition, lifestyle, socio-economic background, medical and dental history. Chief complaints, the onset, duration, progress of the symptoms.

Patients were subjected to intraoral examination to determine the condition of the tooth to be extracted.

\section{B. Radiographic Examination:}

The preoperative evaluation was done by digital standardized intraoral preapical radiographs to evaluate the condition of the teeth, the tooth to be extracted, and to evaluate the alveolar bone at the site of extraction.

Each patient signed a written consent having all the details about the surgical procedures.

\section{Surgical procedure:}

Patients were divided into two groups: group I (graft group) and group II (control group).

\section{In group I (graft group):}

\section{Preoperative evaluation:}

The preoperative evaluation was done by digital standardized intraoral preapical radiograph to evaluate the condition of the tooth to be extracted, and to evaluate the alveolar bone at the site of extraction.

The non-restorable or badly decayed lower molars or premolars was extracted as atraumatic as possible under local anesthesia Mepecaine-L $1.8 \mathrm{ml}$ was used for each extraction.

\section{Preparation of PRF and PRF Membrane:}

1. Using $10 \mathrm{ml}$ of whole blood, were taken from median cubital vein of the patient after extraction in the operating room by a sterile plastic syringe single use and inserted in two $5 \mathrm{ml}$ blood collection tubes without anticoagulant.

2. Immediately after blood draw, the blood collection tubes without anticoagulant and centrifuged at $3000 \mathrm{rpm}$ for 10 minutes at room temperature in the laboratory centrifuge

3. (80-1 electric centrifuge, manufacturer: Changzhou Jiangnan Instrument, China).

4. After centrifugation, the resultant product consists of three layers. The topmost layer consisting of acellular PPP (platelet poor plasma), PRF clot in the middle and RBCs at the bottom of the test tube.

5. The fibrin clot obtained after centrifugation is removed from the tube and the attached red blood cells scraped off from it and discarded.

6. PRF can also be prepared in the form of a membrane by squeezing out the fluids present in the fibrin clot.

Xenograft bone graft (OneGraft natural collagenated bovine bone graft $1.0-2.0 \mathrm{~mm}$ grain size Bioimplon, Germany) submerged in sterile $20 \%$ albumin solution (Human Albumin Grifols, Grifols, UK) for 1 minute under aseptic conditions then mixed with PRF will be inserted in the socket.

\section{In group II (control group):}

\section{Preoperative evaluation:}

The preoperative evaluation was done by digital standardized intraoral preapical radiograph to evaluate the tooth to be extracted, and to evaluate the alveolar bone at the site of extraction.

Intra-oral evaluation of the tooth to be extracted, and alveolar ridge condition at the site of extraction.

Extraction was done as atraumatic as possible to avoid soft tissue and bone destruction .

Patients were instructed to have soft diet without contact of the surgically involved zone. 


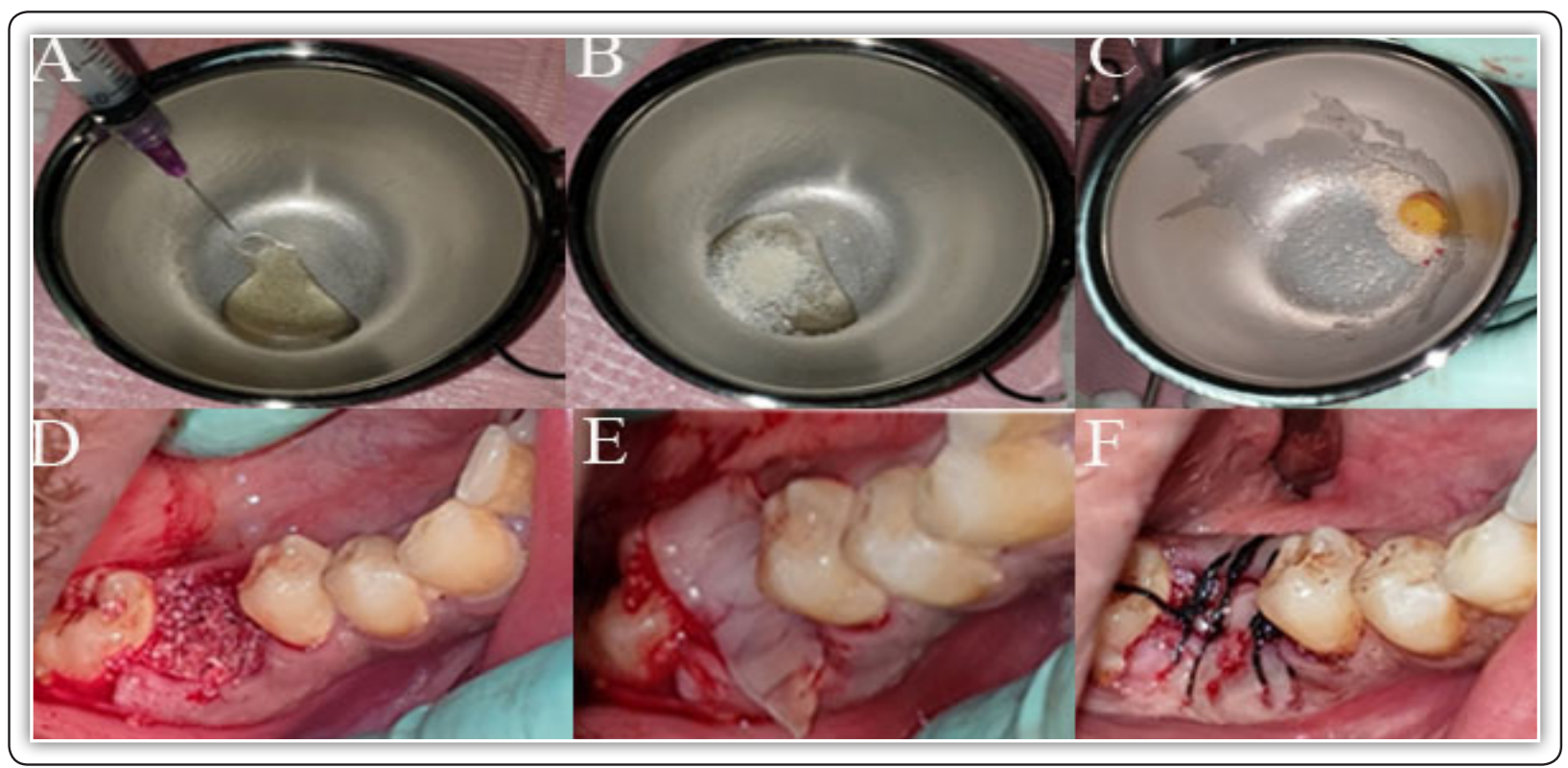

FIG (1) Human albumin solution (A), adding OneGraft xenograft and mixing them for 1 minute (B), adding PRF and mixing them to obtain albumin coated xenograft with PRF $(\mathrm{C})$, insertion of albumin coated xenograft with PRF into the socket (D), covering by PRF membrane (E), suturing the socket with Silk $3.0(\mathrm{~F})$

\section{Post-Operative Instructions:}

All patients were instructed to have soft diet without contact of the surgically involved zone. All patients informed to bite and presses on the gauze pack that have been placed over the surgical site and donot change for one hour, wound healing assessment together with oral hygiene had been followed up by the same investigator regularly after surgery

\section{Medications:}

Systemic Antibiotics, Clavimox 1g (amoxicillin anhydrous $875 \mathrm{mg} /$ clavulanic acid $125 \mathrm{mg}$ produced by pharco pharmaceuticals Alexandria), was taken twice daily for 4 days. Anti-inflammatory, Rapidus 50mg (Tabuk Pharmaceuticals, Egypt) was used to relieve pain and swelling, tablet, every 8 hours for 3 days. Chlorhexidine mouth wash $0.12 \%$ (Macro Group Pharmaceutica) was used twice daily for 3 days Stich was removed at 7 postoperative day. Post-operative assessment: Patients were recalled weekly during the first month. Then after 6 months.
Clinical evaluation: Assessment of soft tissue healing procedure was done at 1 week and for 2 weeks after surgical procedure.

\section{Radiograghic Evaluation:}

CBCT was done to evaluate bone density and alveolar bone height as the following:

A. Alveolar bone height and width measurements. The alveolar bone height and width were evaluated to assess alveolar bone changes after tooth extraction and bone graft application. The measurement was done immediately postoperatively and compared to measurements at 6 months after surgery. The sockets were divided into mesial, middle, and distal regions, the mean value of these points were taken and recorded. Lingual and buccal alveolar bone heights as well as alveolar bone width were measured in each region as following;

(1) The distances from the bottom of the mandible to the top of the alveolar bone of the buccal 


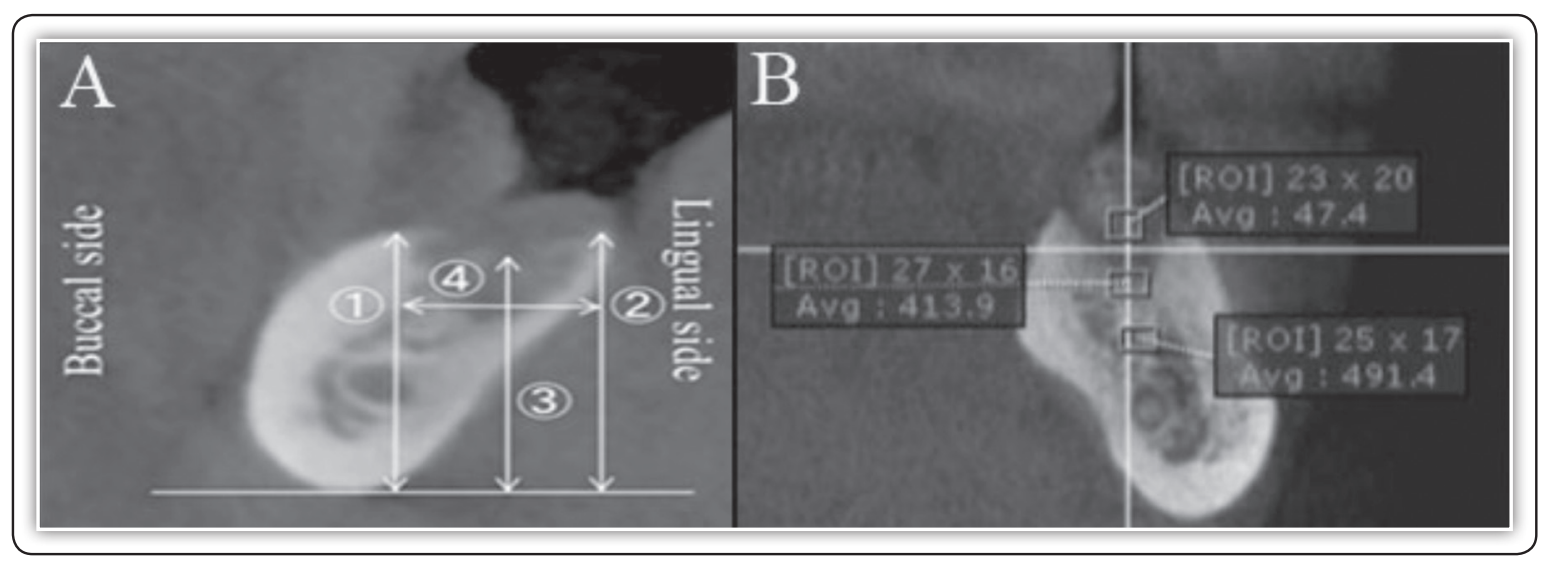

FIG (2) Coronal view CBCT of alveolar bone height \& width measurement at the mesial and distal side (A), Coronal view CBCT showing location of alveolar bone density measurements (B).

side, (2) lingual side; (3) Socket floor; (4) The alveolar bone width is the distance between the reference line (1) and (2) in the mandible. The reference line was set at the bottom of the mandible, (Figure 2).

B. Bone density measurement Bone density was assessed at the site of extraction and bone graft application, immediately \& at 6 months post operatively. Three reading were taken at the region of interest (ROI) at coronal, middle and apex of the sockets at mesial and distal side and at middle region of the sockets, measurement averages were taken and recorded (figure 2).

\section{RESULTS}

\section{Statistical analysis}

Data were fed to the computer and analyzed using IBM SPSS software package version 20.0.

\section{Demographic data}

Twenty patients ranged in age between $20.0-$ 36.0 years with a mean age of $29.90 \pm 5.90$ years for control group and age between 23.0 - 40.0 years with a mean age of $33.20 \pm 5.39$ years for study group. There was no statistically significant difference the groups regarding to the mean of age. Control group had 5 males and 5 females, while study group had 6 males and 4 females. There was no statistically significant difference between gender distributions in the groups.

\section{Clinical evaluation}

The healing of post extraction sites of all patients were uneventful and satisfactory by qualitative clinical regular intervals, no signs of infection in or around the wound sites were observed, and the soft tissue healing progressed normally. One case showed inflammation due to default of oral hygiene period of soft tissue healing, this case was treated by antibiotics and mouth wash.

\section{Radiographic evaluation}

Vertical bone height was assessed with CBCT to determine buccal and lingual bone height which measured from crest of alveolar height to inferior border of the mandible. Also, measurement was done from the bottom of the socket to the inferior border of the mandible. Horizontal measurement was done to determine width of bone. In addition, bone density was measured to determine the efficacy of graft material on bone formation. All measurements were done at mesial, middle and distal of the sockets and the average measurements were taken. 


\section{Alveolar bone height}

\section{A. Buccal bone height}

Study group showed increase in buccal height by $\uparrow 6.33 \pm 9.70 \%$ compared to control group that showed decrease in buccal height by $\downarrow 7.78 \pm 2.29 \%$.

TABLE (1) Showing buccal bone height in all groups immediately \& 6 months post extraction and differences between them

\begin{tabular}{|c|c|c|c|c|}
\hline & $\begin{array}{c}\text { Control } \\
(\mathrm{n}=10)\end{array}$ & $\begin{array}{c}\text { Study } \\
(\mathrm{n}=10)\end{array}$ & \multirow{2}{*}{$\mathrm{U}$} & $\mathrm{p}$ \\
\cline { 2 - 3 } & Mean $\pm \mathrm{SD}$ & Mean $\pm \mathrm{SD}$ & & \\
\hline Buccal height & \multicolumn{5}{|c|}{} \\
\hline Immediately & $24.29 \pm 1.08$ & $26.23 \pm 3.22$ & 36.0 & 0.315 \\
\hline 6 months & $22.38 \pm 0.55$ & $27.62 \pm 1.24$ & $0.0^{*}$ & $<0.001^{*}$ \\
\hline \% Ch. from immediately to \\
\hline 6 months & $\downarrow 7.78 \pm 2.29$ & $\uparrow 6.33 \pm 9.70$ & $2.0^{*}$ & $<0.001^{*}$ \\
\hline
\end{tabular}

U: Mann Whitney test

$p: p$ value for comparing between the studied groups

*: Statistically significant at $p \leq 0.05$

\section{B. Lingual bone height}

Study group showed increase in lingual height by $\uparrow 5.05 \pm 5.49 \%$ compared to control group that showed decrease in lingual height by $\downarrow 7.27 \pm 3.47 \%$.

TABLE (2): Comparison between the two studied groups according to lingual height

\begin{tabular}{|c|c|c|c|c|}
\hline & $\begin{array}{c}\text { Control } \\
(\mathrm{n}=10)\end{array}$ & $\begin{array}{c}\text { Study } \\
(\mathrm{n}=10)\end{array}$ & $\mathrm{U}$ & $\mathrm{p}$ \\
\hline & Mean \pm SD & Mean $\pm \mathrm{SD}$ & & \\
\hline Lingual height \\
\hline Immediately & $24.66 \pm 0.30$ & $26.07 \pm 3.26$ & 50.0 & 1.000 \\
\hline 6 months & $22.87 \pm 0.87$ & $27.24 \pm 2.07$ & $0.0^{*}$ & $<0.001^{*}$ \\
\hline \% Ch. from immediately to \\
\hline 6 6 months & $\downarrow 7.27 \pm 3.47$ & $\uparrow 5.05 \pm 5.49$ & $0.0^{*}$ & $<0.001^{*}$ \\
\hline
\end{tabular}

U: Mann Whitney test

$p: p$ value for comparing between the studied groups

*: Statistically significant at $p \leq 0.05$

\section{Measurement of socket bottom}

Study group showed increase in bottom of socket by $\uparrow 61.11 \pm 56.18 \%$ compared to control group that showed decrease in bottom of socket by $\downarrow 1.34 \pm$ $9.42 \%$.

TABLE (3): Comparison between the two studied groups according to bottom of the socket.

\begin{tabular}{|c|c|c|c|c|}
\hline & $\begin{array}{l}\text { Control } \\
(\mathrm{n}=10)\end{array}$ & $\begin{array}{c}\text { Study } \\
(\mathrm{n}=10)\end{array}$ & \multirow{2}{*}{$\mathrm{U}$} & \multirow{2}{*}{$\mathrm{p}$} \\
\hline & Mean \pm SD & Mean \pm SD & & \\
\hline \multicolumn{5}{|l|}{ Bottom of socket } \\
\hline Immediately & $14.89 \pm 1.57$ & $15.58 \pm 5.24$ & 42.0 & 0.579 \\
\hline 6 months & $14.56 \pm 0.32$ & $23.55 \pm 5.99$ & $20.0^{*}$ & 0.023 \\
\hline \multicolumn{5}{|c|}{$\% \mathrm{Ch}$. from immediately to } \\
\hline 6 months & $\downarrow 1.34 \pm 9.42$ & $\uparrow 61.11 \pm 56.18$ & $15.0^{*}$ & 0.007 \\
\hline
\end{tabular}

U: Mann Whitney test

$p: p$ value for comparing between the studied groups

*: Statistically significant at $p \leq 0.05$

\section{Bone socket width}

Study group showed less decrease in width by $\downarrow 12.51 \%$ compared to control group that showed more decrease in width by $\downarrow 14.28 \%$.

TABLE (4): Comparison between the two studied groups according to width

\begin{tabular}{|c|c|c|c|c|c|c|}
\hline & \multicolumn{2}{|c|}{ Control } & \multicolumn{2}{|c|}{ Study } & \multirow{2}{*}{$\mathbf{U}$} & \multirow{2}{*}{ p } \\
\hline & Mean & \pm SD & Mean & \pm SD & & \\
\hline \multicolumn{7}{|l|}{ Width } \\
\hline Immediate & 7.67 & 1.34 & 8.46 & 1.18 & 25.0 & 0.063 \\
\hline 6 months & 6.58 & 1.18 & 7.39 & 0.93 & 25.0 & 0.063 \\
\hline$\%$ Change & $\downarrow 14.28$ & 0.43 & $\downarrow 12.51$ & 1.13 & $0.0^{*}$ & $<0.001^{*}$ \\
\hline
\end{tabular}

U: Mann Whitney test

$p: p$ value for comparing between the studied groups

*: Statistically significant at $p \leq 0.05$ 


\section{E. Bone density}

Study group showed high density by $\uparrow 236.8 \pm$ $270.6 \%$ compared to control group that showed also increase by $\uparrow 78.73 \pm 83.15 \%$.

TABLE (5): Comparison between the two studied groups according to density

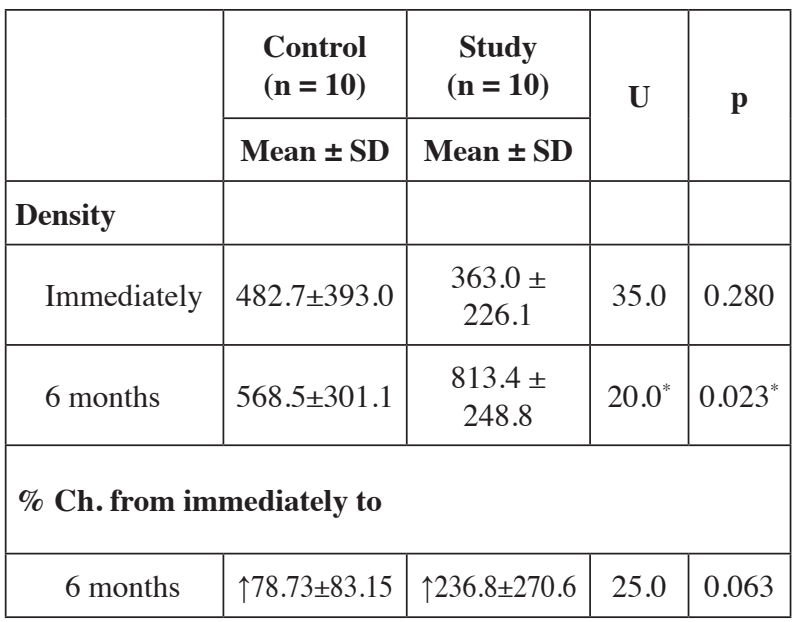

$U:$ Mann Whitney test

$p: p$ value for comparing between the studied groups

*: Statistically significant at $p \leq 0.05$

\section{DISCUSSION}

Ridge alteration is a physiological process that must occur after either single or multiple teeth extraction. Alveolar ridge undergoes resorption in both vertical and horizontal aspects. This ridge loss starts after extraction and continues throughout life, its fastest rate during first three months, and then the rate decreases gradually. Resorption occurs spontaneously in both horizontal and vertical dimensions, but it is more rapid and aggressive in horizontal dimension than in vertical one. Many studies stated that about $50 \%$ of the horizontal dimension was lost after six months Vertical dimension decreases also, it decreases more rapidly on buccal side, after six months vertical dimension decreases by about $1.7 \mathrm{~mm}^{(11,12)}{ }^{\circ}$

The first attempt to preserve the alveolar ridge dimensions was performed by Osburn in $1974^{(13)}$, he used retained roots within the alveolar ridge to minimize bone loss after extraction to increase retention of removable prosthesis.

Radiographic assessment was done by CBCT taken at two stages; $1^{\text {st }}$ stage immediately after extraction as a baseline image, and after six months to be compared to the baseline, to calculate differences in ridge width and height, difference in bone density before and after extraction in both groups. Many studies supported using CBCT as a reliable and accurate diagnostic aid to measure ridge width and height ${ }^{(14)}$, and bone density ${ }^{(15,16)}$.

In previous study comparing hard tissue changes following socket preservation using alloplasts, xenografts vs no grafting both BCS/HA and BDX groups resulted in less vertical and horizontal bone loss following tooth extraction when compared to the nongrafted control. Toloue ${ }^{(17)}$ utilized a calcium sulphate (CS) bone graft and reported somewhat greater horizontal bone loss $(-1.33 \mathrm{~mm})$ as compared to $(-0.25 \mathrm{~mm})$ in the present study, with comparable and minimal vertical bone loss. Willenbacher and co-workers ${ }^{(18)}$ in a systematic review and metaanalysis of socket preservation reported that the weighted mean differences between grafted and nongrafted sites were $1.31-1.54 \mathrm{~mm}$ in the horizontal direction and $0.91-1.12 \mathrm{~mm}$ in the vertical direction. In comparison, in the present study, the differences in the vertical direction were $(3.0 \mathrm{~mm})$ and the differences in the horizontal direction were (1.0-2.46 mm).

Several studies have compared BDX with other alloplasts and achieved mixed results: Shakibaie ${ }^{(19)}$ compared BDX with silicon dioxide/ HA grafting materials for socket preservation. They reported that the dimensions of the ridge at the extraction site were better preserved in the BDX group 
compared to the silicon dioxide/HA or nongrafted sites. Conversely, Kotsakis and colleagues ${ }^{(20)}$ in a similar human study of socket preservation, reported that the CS and the BDX treated groups had comparable dimensional changes that were better than in the nongrafted group. Likewise, Gholami and coworkers ${ }^{(21)}$ in a similar study compared BDX with synthetic nanocrystalline HA reported comparable results with both materials. These differences may be attributed to the different alloplasts that were utilized in these studies, each with its specific physical, chemical and therefore biological properties. Finally, Atieh and colleagues ${ }^{(22)}$ in systematic review and meta analysis of only RCTs of at least 6 months' duration, found only two papers that compared alloplasts vs xenografts with no evidence that either ridge preservation techniques caused a smaller reduction in ridge height or width.

Several previous protocols were introduced in order to improve the remodelling capacity of allografts. Enneking observed in allografts retrieved from patients that markedly better allograft remodeling can be achieved when the graft is mixed with autologous materials such as bone or marrow ${ }^{(23,24)}$.

The use of autologous growth factors separated from blood in the form of platelet rich plasma (PRP) is routinely used in dentistry, however, without solid proof of efficacy ${ }^{(25)}$.

Restoring bone structure proteins such as collagenor fibronectin has been shown to moderately increase the stem cell adherent properties of the scaffold but human albumin coating not only increased seeding efficiency, but also cell proliferation in vitro ${ }^{(7)}$. Since serum albumin in high concentrations is a standard constituent of mesenchymal stem cell media, one may assume that local delivery of serum in the form of coating the allograft surface may have beneficial effects as well ${ }^{(26)}$. In an animal model of bone loss, albumin coating improved the ingrowth of the host bone into the graft, even without adding any exogenous stem cells ${ }^{(7)}$.
The present study was to evaluate albumin coated xenograft with PRF to enhance bone formation and bone height after tooth extraction. CBCT was done to evaluate; bone density, alveolar bone width and height at the site of extraction and bone graft addition. Bone Density, width and height was measured at alveolar bone crest $\&$ middle of the socket at region of interest (ROI) immediately \& at 6 months post operatively.

\section{CONCLUSION}

The use of albumin coated xenograft with PRF in the present study was effective in socket preservation, significantly minimized ridge resorption in all dimensions with increase the quality bone and was observed in the study group.

\section{REFERENCES}

1. Araújo MG, Lindhe J. Dimensional ridge alterations following tooth extraction. An experimental study in the dog. J Clin Periodontol. 2005;32(2):212-8.

2. Lekovic V, Kenney EB, Weinlaender M, Han T, Klokkevold P, Nedic M, et al. A bone regenerative approach to alveolar ridge maintenance following tooth extraction. Report of 10 cases. J Periodontol. 1997;68(6):563-70.

3. Bae J, Kim Y, Myung S. Effects of platelet rich plasma on sinus bone graft: Meta analysis. J Periodontol. 2011;82(5):660-7.

4. Bae HW, Zhao L, Kanim LEA, Wong P, Delamarter RB, Dawson EG. Intervariability and intravariability of bone morphogenetic proteins in commercially available demineralized bone matrix products. Spine (Phila Pa 1976). 2006;31(12):1299-306.

5. Bishop GB, Einhorn TA. Current and future clinical applications of bone morphogenetic proteins in orthopaedic trauma surgery. Int Orthop. 2007;31(6):721-7.

6. Pecina M, Haspl M, Jelic M, Vukicevic S. Repair of a resistant tibial non-union with a recombinant bone morphogenetic protein-7 (rh-BMP-7). Int Orthop. 2003;27(5):320-1.

7. Weszl M, Skaliczki G, Cselenyák A, Kiss L, Major T, Schandl K, et al. Freeze dried human serum albumin improves the adherence and proliferation of mesenchymal stem cells on mineralized human bone allografts. J Orthop Res. 2012;30(3):489-96. 
8. Skaliczki G, Schandl K, Weszl M, Major T, Kovács M, Skaliczki J, et al. Serum albumin enhances bone healing in a nonunion femoral defect model in rats: a computer tomography micromorphometry study. Int Orthop. 2013;37(4):741-5.

9. Klára T, Csönge L, Janositz G, Csernátony Z, Lacza Z. Albumin-coated structural lyophilized bone allografts: a clinical report of 10 cases. Cell Tissue Bank. 2014;15(1):89-97.

10. Das S, Jhingran R, Bains VK, Madan R, Srivastava R, Rizvi I. Socket preservation by beta-tri-calcium phosphate with collagen compared to platelet-rich fibrin: A clinicoradiographic study. Eur J Dent. 2016;10(2):264-76.

11. Vittorini Orgeas G, Clementini M, De Risi V, de Sanctis M. Surgical techniques for alveolar socket preservation: a systematic review. Int J Oral Maxillofac Implants. 2013;28(4):1049-61.

12. Horowitz R, Holtzclaw D, Rosen PS. A review on alveolar ridge preservation following tooth extraction. J Evid Based Dent Pract. 2012 Sep;12(3 Suppl):149-60.

13. Osburn RC. Preservation of the alveolar ridge: a simplified technique for retaining teeth beneath removable appliances. J Indiana State Dent Assoc. 1974;53(1):8-11.

14. Roe P, Kan JYK, Rungcharassaeng K, Caruso JM, Zimmerman G, Mesquida J. Horizontal and vertical dimensional changes of peri-implant facial bone following immediate placement and provisionalization of maxillary anterior single implants: a 1-year cone beam computed tomography study. Int $\mathrm{J}$ Oral Maxillofac Implants. 2012;27(2):393-400.

15. Norton MR, Gamble C. Bone classification: an objective scale of bone density using the computerized tomography scan. Clin Oral Implants Res. 2001 Feb;12(1):79-84.

16. Aranyarachkul P, Caruso J, Gantes B, Schulz E, Riggs M, Dus I, et al. Bone density assessments of dental implant sites: 2. Quantitative cone-beam computerized tomography. Int J Oral Maxillofac Implants. 2005;20(3):416-24.
17. Toloue SM, Chesnoiu Matei I, Blanchard SB. A clinical and histomorphometric study of calcium sulfate compared with freeze dried bone allograft for alveolar ridge preservation. J Periodontol. 2012;83(7):847-55.

18. Willenbacher M, Al Nawas B, Berres M, Kämmerer PW, Schiegnitz E. The effects of alveolar ridge preservation: a meta analysis. Clin Implant Dent Relat Res. 2016;18(6):1248-68.

19. Shakibaie-M B. Comparison of the effectiveness of two different bone substitute materials for socket preservation after tooth extraction: a controlled clinical study. Int J Periodontics Restorative Dent. 2013;33(2).

20. Kotsakis GA, Salama M, Chrepa V, Hinrichs JE, Gaillard P. A randomized, blinded, controlled clinical study of particulate anorganic bovine bone mineral and calcium phosphosilicate putty bone substitutes for socket preservation. Int J Oral Maxillofac Implants. 2014;29(1).

21. Gholami GA, Najafi B, Mashhadiabbas F, Goetz W, Najafi S. Clinical, histologic and histomorphometric evaluation of socket preservation using a synthetic nanocrystalline hydroxyapatite in comparison with a bovine xenograft: a randomized clinical trial. Clin Oral Implants Res. 2012; 23(10):1198-204.

22. Atieh MA, Alsabeeha NHM, Payne AGT, Duncan W, Faggion $\mathrm{CM}$, Esposito M. Interventions for replacing missing teeth: alveolar ridge preservation techniques for dental implant site development. Cochrane Database Syst Rev. 2015;(5).

23. Enneking WF, Campanacci DA. Retrieved human allografts: a clinicopathological study. JBJS. 2001; 83(7):971-86.

24. Enneking WF, Mindell ER. Observations on massive retrieved human allografts. JBJS. 1991;73(8):1123-42.

25. Intini $G$. The use of platelet-rich plasma in bone reconstruction therapy. Biomaterials. 2009;30(28):4956-66.

26. Ryser MF, Thieme S, Bornhäuser M, Lehmann R, Brenner S. Serum albumin strongly influences SDF-1 dependent migration. Int J Hematol. 2009;89(3):269-75. 